\title{
Research on External Supervision System of National Supervisory Power
}

\author{
Sihan $\operatorname{Liu}^{1, *}$ \\ ${ }^{1}$ School of Law and Society, Wuhan University of Technology, Wuhan, Hubei 430070, China \\ *Corresponding author. Email: 1146937627@qq.com
}

\begin{abstract}
At present, the national supervision system with Chinese characteristics has been initially formed, and the national supervision power has become a new type of power, which has the characteristics of high status, heavy power and wide scope. Beginning with the pilot reform of the national supervisory system, research on national supervisory power has always been a hot topic in academia. This article takes the new policies and regulations under the reform of the national supervisory system as the starting point, and recognizes the problems existing in the external supervision system of the national supervisory power at the current stage. And social supervision is weak. In response to the above problems, this article puts forward suggestions on how to perfect the external supervision system of the state's supervision power.
\end{abstract}

Keywords: reform of the state supervision system, supervisory authority, supervision and restriction

\section{INTRODUCTION}

The national supervisory power is a new type of power, which realizes the integration of the administrative supervisory power and the administrative violation prevention power that originally belonged to the government. , Heavy power, wide range and other characteristics. In order to prevent the Supervisory Commission from becoming a supreme body that overrides the law and has excessively expanded powers, it is necessary to discuss how to supervise the national supervisory power.

At present, academic research on the supervision of the national supervisory power is still immature. At the theoretical level, there are disputes and discussions on the nature and characteristics of the national supervisory power; at the practical level, the construction and design of the supervisory system for the national supervisory power The peace and operation is not yet perfect, and there are vague rules of principle and program.

\section{MAIN PROBLEMS EXISTING IN THE STATE} \section{SUPERVISION SYSTEM OF EXTERNAL} SUPERVISION

Based on the theory of people's sovereignty, China has constructed the system of people's congress. The supervision method of the people's congress to the supervisory organ should include the following three

*Fund: the Excellent Dissertation Cultivation Funds of Wuhan University of Technology (2018-YS-095) aspects: first, the supervision of the personnel of the supervisory commission, namely the exercise of the power of the people's congress to appoint and appoint personnel. Therefore, the members of the supervisory committee are elected or appointed by the people's congress, and the people's congress can inquire, remove, and supervise them. This is the most important way of supervision by the National People's Congress. The National People 's Congress conducts a work report. The National People's Congress can form a specific investigation committee under specific circumstances to directly supervise the Supervisory Committee. Finally, legal supervision of the Supervisory Committee is implemented, making the supervision power of the supervision committee operate within the legal authority and legal procedures.

The Constitution of our country stipulates that the supervisory organs should cooperate with and restrain each other in handling cases of duty violations and crimes with the judicial organs, procuratorial organs, and law enforcement agencies. This provision provides a legal basis for the power allocation of the supervisory committee, the people's court, the people's procuratorate, and the public security organ. Formally, Article 127 of the Constitution stipulates the two-way cooperation and restriction relationship of the state organs led by the supervisory organs. However, from the perspective of the macro-structure of state power, the newly amended Constitution after the reform of the supervisory system has not been systematically and systematically rewritten The configuration and adjustment of the relationship between various state 
organs only stipulates the relationship between state organs individually through decentralized clauses, leading to a certain degree of regulatory structural flaws in the coordination and restriction of state organs.

From the perspective of law hierarchy, "mutual cooperation and mutual restriction" is a principle with constitutional rank. The principle has a low degree of certainty and insufficient guidance. If there is no guidance from specific rules, the applicability of the principle will inevitably be weakened, and the boundary of cooperation and restriction relationship cannot be accurately grasped. From the perspective of practical operation, after the reform, the anti-corruption and antireading departments and personnel of the procuratorate were transferred to the supervisory commission, and the legal supervision function of the procuratorate was "weakened" and only the power of public prosecution and part of the power of investigation were retained. The supervisory power of the supervisory committee at the same level is stronger than that of the procuratorial power of the procuratorate.

Supervisory commission as a special national watchdog, Democratic Party give play to the role of democratic supervision is a new important channel, but with inner-party supervision, supervision of National People's Congress, the judicial organs such as supervision type, lack of innovation in the supervision form, there is no rigid constraints on surveillance, poor feedback in monitoring results.

First of all, the level of institutionalization of democratic supervision over the supervision of the country's supervision power needs to be improved. Institutionalization of democratic supervision includes the normalization of supervision content, the fixed form of supervision and the regularization of supervision procedures. The basic requirement is to abide by a complete set of laws and regulations, and the opinions, suggestions, and criticisms of various democratic parties must be handled in accordance with standard procedures. At present, some achievements have been made in the institutionalization of democratic supervision, but there are still some problems with the democratic supervision of the state's supervision power. The system of democratic supervision for the supervision of the state 's supervision power is not perfect, lacking specific procedures and uniform methods, and lacking clear regulations on the relationship between the supervisor and the supervised, as well as the principles, content, procedures, responsibilities and obligations of the supervised.

Secondly, the ability of democratic supervision to supervise the state's supervision power needs to be strengthened. The effect of democratic supervision is closely related to the ability of democratic supervision. Compared with the ability of political parties to consult, participate in and discuss politics, the ability of democratic supervision is a weakness of the ability of participating parties, which is mainly caused by subjective and objective reasons. From an objective point of view, the ability of democratic supervision is not compulsory, and is an auxiliary ability. It has a strong dependence on the ruling party and government in the political life of the country, including dependence on relevant information, political resources, and activity funds. . The effectiveness of supervision depends not only on the democratic parties themselves, but also on the ruling party. From a subjective perspective, the initiative or willingness of democratic supervision is not strong.

From the perspective of the subject of supervision, although the quality of citizens has improved significantly in recent years, the overall level is relatively low. With the continuous and in-depth development of comprehensively governing the country according to law, especially the modern legal awareness and quality of citizens need to be improved. Citizens' overall sense of supervision responsibility is relatively weak, ignoring their own responsibility for supervision.

From the perspective of the object of supervision, the object of supervision is the state organs and their staff who exercise the public power of the state, including the supervision committee and its staff who exercise the power of state supervision. Some public officials have no willingness to take the initiative to accept supervision because of incorrect power concepts; some public officials believe that supervision is distrust and have serious resistance to supervision; some public officials believe that supervision affects administrative efficiency and hinders their creativity. Therefore, deliberately set up barriers to information exchange, not to disclose the specific administrative decision-making procedures and content, resulting in "information asymmetry", and thought to try to create obstacles for supervision to bypass supervision. These erroneous concepts of power and misunderstanding of supervision have largely affected the normal and orderly development of supervision of the state's supervision power.

\section{SUGGESTIONS ON THE EXTERNAL SUPERVISION SYSTEM OF NATIONAL SUPERVISORY POWER}

As for the preparatory work for starting the supervisory power, verifying the clues is a necessary prerequisite for the supervisory organ to file a case of duty crime. In general, the ways in which supervisory agencies obtain clues about public officials' crimes and crimes usually include: citizens' reports and accusations, other authorities' handovers after the clues are found, supervision and oversight discovery, proactive confession and other sources. It only mentions the need to set up an investigation team, 
without specific details. Procuratorial organs should be given the right to spot-check the disposal plans made by the supervisory organs for clues to problems.

In the case filing procedure, the supervisory authority filed a case for a duty crime. Although it is part of the supervisory authority 's independent exercise of its supervisory powers in accordance with the law, it should not be subject to external interference. Various degrees of punishment will have a decisive role in whether to enter the criminal accountability process. Therefore, it is necessary to study the procedure of filing the case carefully and do a good job of differentiation to prevent problems at the source and lead to deviations in the direction of handling the case. Supervision can be carried out through the following two aspects: First, the respective standards for filing cases of duty violations and duty crimes should be specified. According to the relevant provisions of the "Criminal Procedure Law", the standard of criminal proceedings can be directly applied to the filing procedures of the supervisory organs, which does not destroy the scale of the criminal case filing, but also lays the foundation for the later prosecution organs to review and prosecute. Secondly, establish a filing system, and record and record the two types of cases in the process of filing and diversion, indicate the reason for the diversion and the opinions of the responsible person, and transfer the record to the procuratorial organ with the case file.

In addition, it is necessary to improve the supervision and compensation system. Article 67 of the Supervision Law stipulates, "If the supervisory organ and its staff exercise their powers and infringe upon the legitimate rights and interests of citizens, legal persons and other organizations and cause damage, the state shall be compensated according to the law." The current regulations of the supervisory compensation system are relatively simple, The National Compensation Law does not specify the system design for monitoring compensation, and there are no clear regulations on issues such as the principle of liability, organs of compensation obligations, and scope of compensation.

First, it is necessary to establish the principle of imputation of supervisory compensation. As a principle provision of the general provisions of the state compensation law, the principle of imputation plays a guiding role in the design of the supervisory compensation system. Due to the particularity of the organ under compensatory obligation, that is, the supervisory organ, which is quite different from the administrative and judicial compensation, the principle of liability attribution of the supervisory compensation system should be determined separately. The system of supervision and compensation should adopt the principle of imputation of "illegal and no-fault", and promote the transformation of the principle of imputation of administrative compensation from a single illegal principle to a multi-rule system of illegal and no-fault, so as to form an organic whole of administrative, judicial and supervisory compensation.

Second, to determine the supervision of the indemnity obligatory agency. Under the supervision system reform, the design of the "office office" system for discipline inspection and supervision organs is the most important problem involved in compensation. The central question is whether the discipline inspection authority can be the defendant in the compensation. What needs to be made clear is that the discipline inspection commission cannot be the defendant in the compensation litigation, because the discipline inspection commission is not a state organ, but a party department. Therefore, the supervisory indemnity obligatory agency should be clearly defined as the supervisory commission at all levels.

\section{CONCLUSION}

This paper recognizes the problems existing in the external supervision system of the national supervisory right at the present stage, one is that the external supervision system of the national supervisory right is not perfect, the other is that the right relief approach of the supervision object is blocked. Third, social supervision is weak. In view of the above problems, this paper puts forward some Suggestions on how to perfect the external supervision system of national supervisory right. First of all, it is necessary to improve the external supervision system of national supervision right, and secondly, it is necessary to unblock the right relief channels of supervision object.

\section{References}

[1] Qin Qianhong. The logic and method of reforming the supervision system[J]. Universal Legal Review, 2017(2): $17 \sim 27$.

[2] Tong Zhiwei. The Strategy of Bringing the Supervision System Reform into the Rule of Law[J]. Jurisprudence, 2016(12): 3 13.

[3] Han Dayuan. On Some Constitutional Issues in the Reform of National Supervision System[J]. Jurisprudence review, 2017(3): $11 \sim 22$.

[4] Jefffrey Becker. Tackling Corruption at its Source: The National Corruption Prevention Bureau[J]. Journal of Chinese Political Science,2008,13(3): 287 303.

[5] CHRISTIAN M KUTA. Universities,Corporations,and States Use Them - Now It's Time to Protect Them:An Analysis of the Public and Private Sector Ombudsman and the Continued Need For A Privileged Relationship[J]. Southern Illinois University Law Journal, 2003(27):390.

[6] Liu Zhenyang. On the Basic Problems and Specific Paths of the Reconstruction of the National Supervision System[J]. Law Science, 2017 (5): 117-125.

[7] Chen Guangzhong. Several Views on the Reform of Supervisory System [J]. Global Law Review, 2017 (2): 115 117. 